\title{
Attenuation of $\beta$-Amyloid Deposition and Neurotoxicity by Chemogenetic Modulation of Neural Activity
}

\author{
DPeng Yuan (袁鹏) ${ }^{1,2}$ and Jaime Grutzendler ${ }^{1,2}$ \\ Departments of ${ }^{1}$ Neurology and ${ }^{2}$ Neuroscience, Yale University, New Haven, Connecticut 06510
}

\begin{abstract}
Aberrant neural hyperactivity has been observed in early stages of Alzheimer's disease (AD) and may be a driving force in the progression of amyloid pathology. Evidence for this includes the findings that neural activity may modulate $\beta$-amyloid (A $\beta$ ) peptide secretion and experimental stimulation of neural activity can increase amyloid deposition. However, whether long-term attenuation of neural activity prevents the buildup of amyloid plaques and associated neural pathologies remains unknown. Using viral-mediated delivery of designer receptors exclusively activated by designer drugs (DREADDs), we show in two AD-like mouse models that chronic intermittent increases or reductions of activity have opposite effects on $\mathrm{A} \beta$ deposition. Neural activity reduction markedly decreases $\mathrm{A} \beta$ aggregation in regions containing axons or dendrites of DREADD-expressing neurons, suggesting the involvement of synaptic and nonsynaptic $\mathrm{A} \beta$ release mechanisms. Importantly, activity attenuation is associated with a reduction in axonal dystrophy and synaptic loss around amyloid plaques. Thus, modulation of neural activity could constitute a potential therapeutic strategy for ameliorating amyloid-induced pathology in AD.
\end{abstract}

Key words: Alzheimer's disease; amyloid plaque; axonal dystrophy; DREADD; neural activity

Significance Statement

A novel chemogenetic approach to upregulate and downregulate neuronal activity in Alzheimer's disease (AD) mice was implemented. This led to the first demonstration that chronic intermittent attenuation of neuronal activity in vivo significantly reduces amyloid deposition. The study also demonstrates that modulation of $\beta$-amyloid $(\mathrm{A} \beta)$ release can occur at both axonal and dendritic fields, suggesting the involvement of synaptic and nonsynaptic $A \beta$ release mechanisms. Activity reductions also led to attenuation of the synaptic pathology associated with amyloid plaques. Therefore, chronic attenuation of neuronal activity could constitute a novel therapeutic approach for AD.

\section{Introduction}

The role of aberrant patterns of neural activity in the pathogenesis of Alzheimer's disease (AD) is an issue of critical importance. Neural hyperactivity is known to occur at early stages of amyloid deposition in both mouse models (Palop et al., 2007; Busche et al., 2008) and human AD (Dickerson et al., 2005; Elman et al., 2014), pointing to significant neural circuit functional reorganization. Neural activity has also been shown to be an important

Received July 2, 2015; revised Oct. 22, 2015; accepted Dec. 2, 2015.

Author contributions: P.Y. and J.G. designed research; P.Y. performed research; P.Y. contributed unpublished reagents/analytic tools; P.Y. and J.G. analyzed data; P.Y. and J.G. wrote the paper.

This project was supported by National Institutes of Health Grants R01HL106815 and R21AG048181 (J.G.). We thank Drs. R. Vassar (Northwestern University, Evanston, IL) for providing 5xFAD mice and B. Roth (University of North Carolina, Chapel Hill, NC) for providing the DREADD constructs. We thank W. Nowak (Yale University, New Haven, (T) for sharing her expertise and knowledge in biochemistry and R.A. Hill and A.M. Li (Yale University) for critical reading of this manuscript.

The authors declare no competing financial interests.

Correspondence should be addressed to Jaime Grutzendler, 300 George Street, Room 8300G, New Haven, CT 06511. E-mail: jaime.grutzendler@yale.edu.

DOI:10.1523/JNEUROSCI.2531-15.2016

Copyright $\odot 2016$ the authors $\quad 0270-6474 / 16 / 360632-10 \$ 15.00 / 0$ modulator of $\beta$-amyloid $(\mathrm{A} \beta)$ peptide secretion in various experimental settings (Kamenetz et al., 2003; Cirrito et al., 2005; Bero et al., 2011). This raises the possibility that chronic neural hyperactivity could cause a vicious cycle in which elevations of interstitial $\mathrm{A} \beta$ lead to additional exacerbation of amyloid deposition and neural circuit dysfunction. In support of this view, chronically elevating neural activity through stabilized step-function optogenetics has been shown recently to worsen amyloid deposition (Yamamoto et al., 2015). Therefore, we hypothesized that chronic attenuation of neural excitability could break this vicious cycle and lead to a reduction of amyloid plaque formation. This study implements for the first time a chemogenetic approach to test the long-term effects of modulating neuronal activity on both amyloid deposition and axonal and synaptic abnormalities around plaques.

\section{Materials and Methods}

Adeno-associated virus constructs and virus production. hM4D and hM3D sequences were amplified from original constructs provided by the laboratory of Dr. Bryan Roth (catalog \#50463 and \#50464; Addgene). The 

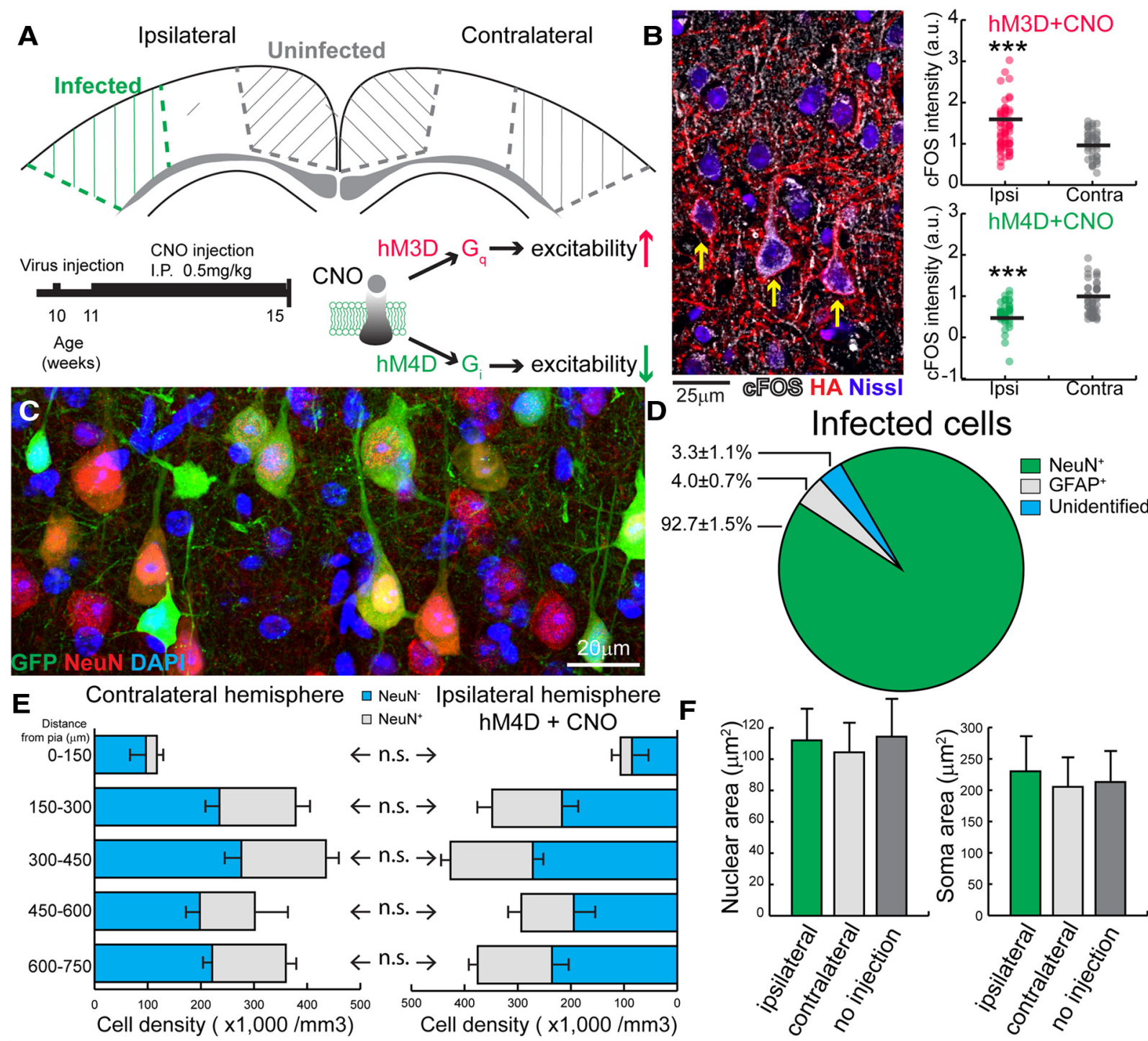

D

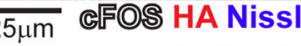

Infected cells
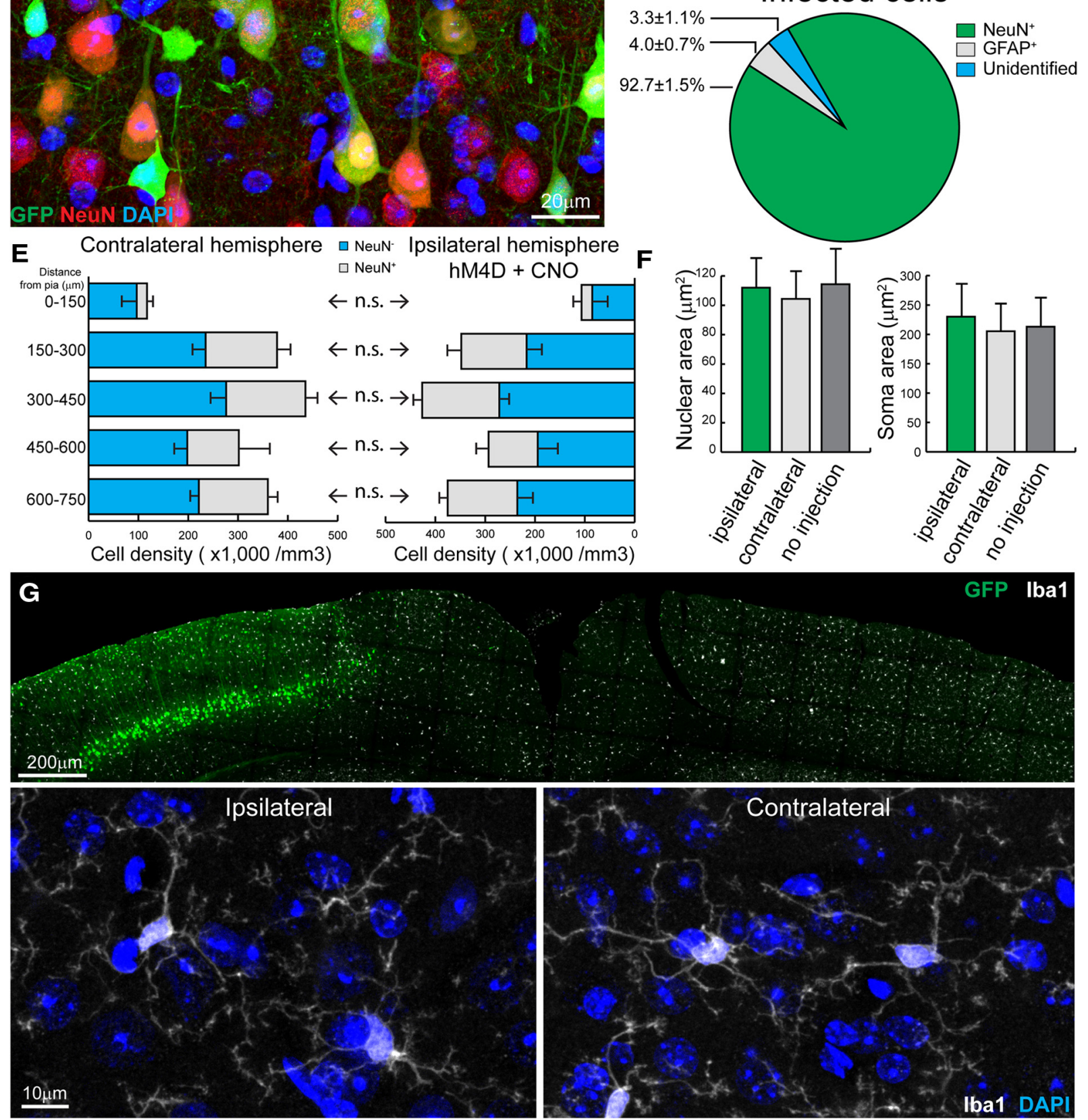

Figure 1. Chemogenetic treatment modulates neural activity without causing inflammation or neurotoxicity. $A$, Schematics and experimental timeline of chemogenetic treatment of the mouse cortex. $\boldsymbol{B}$, Representative confocal images and quantification of c-Fos immunohistochemistry in the cortex of mice receiving DREADD plus CNO treatment. Yellow arrows indicate cells expressing HA-hM3D (red; HA was used as a tag for detecting DREADDs). Nissl stain (blue) highlights neuronal cell bodies. $n=50$ cells compiled from three animals in (Figure legend continues.) 
sequences were inserted into an adeno-associated virus (AAV)packaging plasmid, at the $3^{\prime}$ end of a P2A sequence (Kim et al., 2011) in the same open reading frame. The expression of these constructs was driven by CAG promoter with woodchuck posttranscriptional regulatory element and SV40 sequences at the $3^{\prime}$ end. An HA-tag sequence was fused to the $5^{\prime}$ end of designer receptors exclusively activated by designer drug (DREADD) sequences for expression verification by anti-HA immunohistochemistry. A pDP2rs packaging plasmid (PlasmidFactory) was used to produce the AAV2 virus. Procedures involving virus production and purification are described in our previous work (Condello et al., 2015).

Animal. All animal experimental procedures approved by the Institutional Animal Care and Use Committee at Yale University. The 5XFAD mouse model used in this study (courtesy of Dr. Robert Vassar, Northwestern University, Evanston, IL) overexpresses both human amyloid precursor protein (APP) gene with KM670/671/NL, V717I, and I716V mutations and human PS1 harboring M146L and L286V mutations under the Thyl promoter. The PS/APP mouse model used in this study (catalog \#034832; The Jackson Laboratory) overexpresses human APP gene with KM670/671/NL mutation and DeltaE9 mutation of human PS1 gene under the prion protein complex promoter. Combined agematched litters of male 10-week-old (5XFAD) or 4-month-old (PS/APP) mice were used for experiments. 5XFAD mice were used for all experiments, and PS/APP mice were used to confirm the effect of hM4D plus clozapine-N-oxide (CNO) treatment (see Figs. $2 \mathrm{H}, \mathrm{I}, 3 \mathrm{~A}$ ). The viral vector was diluted in artificial CSF and infused into the subarachnoid space (4.0 $\mathrm{mm}$ posterior, $2.5 \mathrm{~mm}$ lateral from bregma) or CA1 (2.3 mm posterior, 2.0 $\mathrm{mm}$ lateral from bregma, $1.0 \mathrm{~mm}$ deep). Mice were injected with (E,E)-1fluoro-2,5-bis(3-hydroxycarbonyl-4-hydroxy)styrylbenzene (FSB) (7.5 mg/ kg, i.p.; sc-359845; Santa Cruz Biotechnology) on the day of virus injection. Clozapine- $N$-oxide $(0.5 \mathrm{mg} / \mathrm{kg}$, i.p.; catalog \#4936; Tocris Bioscience) treatment started on day 7 after injection, at 7:00 P.M. daily. The mouse brains were collected and fixed with 4\% PFA solution before processing for imaging.

Immunohistochemistry. Coronal brain sections were cut (30 $\mu \mathrm{m}$ thick) with a vibratome (VT1000S; Leica). Heat-induced antigen retrieval was performed for anti-APP C-terminal antibody and anti-c-Fos staining. Primary antibody was diluted in PBS with $0.2 \%$ Triton X-100 and $4 \%$ goat serum (catalog \#005-000-121; Jackson ImmunoResearch). Sections were stained for $2 \mathrm{~d}$ at $4^{\circ} \mathrm{C}$ and then washed and stained with secondary antibodies for $6 \mathrm{~h}$ before mounting to slides.

The following antibodies and stains were used in this study: antiLamp1 antibody (1D4B; Developmental Studies Hybridoma Bank), anti-neuronal nuclei (NeuN) antibody (MAB377; EMD Millipore), fluorescent Nissl stain (N-21482; Thermo Fisher Scientific), anti-c-Fos antibody (ab7963; Abcam), anti-HA epitope tag antibody (catalog \#ETHA100; Aves Labs), anti- $\alpha$-Tubulin antibody (T6199; Sigma-Aldrich), anti-GFP antibody (GFP-1020; Aves Labs), anti-PSD95 antibody (18258; Abcam), anti-APP recognizing N-terminal antibody (LN27; Thermo Fisher Scientific), anti-APP recognizing C-terminal antibody (ZMD.316; Thermo Fisher Scientific), anti- $\beta$-site APP-cleaving enzyme 1 (BACE1) antibody (5606; Cell Signaling Technology), anti-neprilysin (NEP) antibody (AB5458; EMD Millipore), anti-insulin-degrading enzyme (IDE) antibody (ab32216; Abcam), anti-Iba1 polyclonal antibody (019-19741; Wako), anti-GFAP antibody (Z0334; Dako), OC antibody (AB2286; EMD Millipore), anti-A $\beta$ (2454; Cell Signaling Technology), Alexa Fluor-conjugated IgGs (Thermo Fisher Scientific), thioflavin S (T1892; Sigma-Aldrich), curcumin (08511; Sigma-Aldrich), and DAPI (D9542; Sigma-Aldrich).

\footnotetext{
(Figure legend continued.) each ipsilateral and contralateral side groups. ${ }^{* * *} p<0.001$. C, Confocal image of NeuN and DAPI stains in the infected region. $\boldsymbol{D}$, Relative proportion of the various infected cell types in layer IV-VI of the ipsilateral hemisphere. $\boldsymbol{E}$, Mice that had received unilateral hM4D plus CNO treatment did not demonstrate differences in cell or neuron number, $n=6$ mice. $\boldsymbol{F}$, No difference in nuclear or soma size was detected between mice that had received hM4D plus CNO treatment and controls. $n=6$ mice, 150 cells in each group. G, Image of Iba1 labeling showing no changes in the normal distribution or morphology of microglia in ipsilateral and contralateral sites after hM4D plus CNO treatment.
}

Confocal microscopy. A Leica SP5 system was used to collect all confocal images. The laser and detector were maintained at constant settings when imaging each staining set. In all quantifications, plaque counts were obtained from three brain slices encompassing the infected region in each mouse. Infected cortical regions included posterior parietal association areas and posterior somatosensory cortex. Retrosplenial areas were used as uninfected control regions. All analyses used $z$ projections of three optical slices at the center of the plaque or cell.

For analyses of amyloid plaque number and size and neuritic dystrophy size, tiled images across both hemispheres were captured from each brain slice using a $63 \times$ oil-immersion objective [numerical aperture (NA) 1.4] in zoom 1 with a $10 \%$ overlap. Images were captured at $1024 \times$ 1024 pixel resolution with $z$-step size of $3 \mu \mathrm{m}$. Stitched images were processed with FIJI (NIH ImageJ) software with customized macros to segment each individual plaque. Each segmented plaque generated a new image file with a random number as the file name. The use of Lamp1 immunostaining to measure the size of neuritic dystrophy has been verified comprehensively and described in detail in our previous publications using comparative immunohistochemistry and electron microscopy (Condello et al., 2011, 2015; Gowrishankar et al., 2015). In addition, anti-APP staining was also used to measure the size of neuritic dystrophy (see Fig. 4G).

For analyzing c-Fos fluorescence intensity, tissues were costained with fluorescent Nissl, DAPI, and anti-HA tag antibody. Images were acquired using a $40 \times$ oil-immersion objective (NA 1.3) in zoom 2 at $1024 \times 1024$ pixel resolution with $1 \mu \mathrm{m} z$-step size. Anti-HA staining was used to identify infected cells and axon terminals of infected cells. In the contralateral hemisphere, cells were chosen randomly within the layer $\mathrm{V}$ cortex and lateral posterior (LP) nucleus. A $3 \mu \mathrm{m} z$ projection from the center of each neuron was made for fluorescence intensity measurement. The fluorescence intensity of c-Fos staining was measured within the neuronal somata defined by the outlines of the Nissl staining. All intensities were normalized to DAPI labeling intensities to correct for variations in tissue depth.

For analysis of $A \beta$ halo and PSD95, images of individual plaque were acquired using a $63 \times$ oil-immersion objective (NA 1.4) in zoom 4 at $1024 \times 1024$ pixel resolution with $z$-step size of $0.5 \mu \mathrm{m}$. The PSD95 fluorescence were converted to binary values using image mean fluorescence intensity as the threshold. PSD95 puncta were identified using "Analyze Particle" in FIJI within size of $0.01-3 \mu \mathrm{m}^{2}$. PSD95 density was then calculated by dividing the total number of PSD95 puncta by the corresponding area of the doughnut-shaped region. The density at $8 \mu \mathrm{m}$ away from the plaque edge was used as baseline.

For analyzing APP, BACE1, NeuN, NEP, and IDE intensities, images were taken using a $20 \times$ air objective (NA 0.7) at zoom 1 at $1024 \times 1024$ pixel resolution, with a $z$-step size of $1 \mu \mathrm{m}$. Neuronal somata were traced manually using NeuN channel. The fluorescence intensity of each immunochemical stain was then measured inside the manually traced neuronal outlines. All intensities were normalized to DAPI nuclei labeling intensities to correct for variations in imaging attributable to tissue depth.

ELISA. Ipsilateral cortical regions expressing hM4D and corresponding contralateral regions were microdissected from fixed brain slices for protein extraction. hM4D expression is identifiable by its coexpression with GFP, which can be visualized using blue LED illumination and a pair of green filter glasses (BlueStar flashlight packages; NIGHTSEA). Ten brain slices with 30 $\mu \mathrm{m}$ thickness were processed for each mouse. The tissues were washed with PBS for three times and then processed for de-crosslinking and protein extraction following the instructions of the manufacturer (Qproteome FFPE tissue kit; 37623; Qiagen). Protein concentrations were determined by A280 absorption (NanoDrop 2000; Thermo Fisher Scientific) and adjusted to 10 $\mathrm{mg} / \mathrm{ml}$ with double-distilled $\mathrm{H}_{2} \mathrm{O}$.

ELISA was performed on the extracted protein samples to detect $\mathrm{A} \beta_{42}$ (KHB3441; Thermo Fisher Scientific) and $\mathrm{A} \beta_{40}$ (KHB3481; Thermo Fisher Scientific) following the instructions of the manufacturer. Serial 1:1 dilutions were made for each sample to ensure that $A \beta$ concentrations were within the range of the standard curve. Average reads from three repeats were recorded for each sample.

Statistics. Data are represented as mean \pm SEM. Histogram plots were used to observe approximate Gaussian distributions, on which two-tail 
A mCherry-P2A-hM3D DAPI Lamp1 Thioflavin S
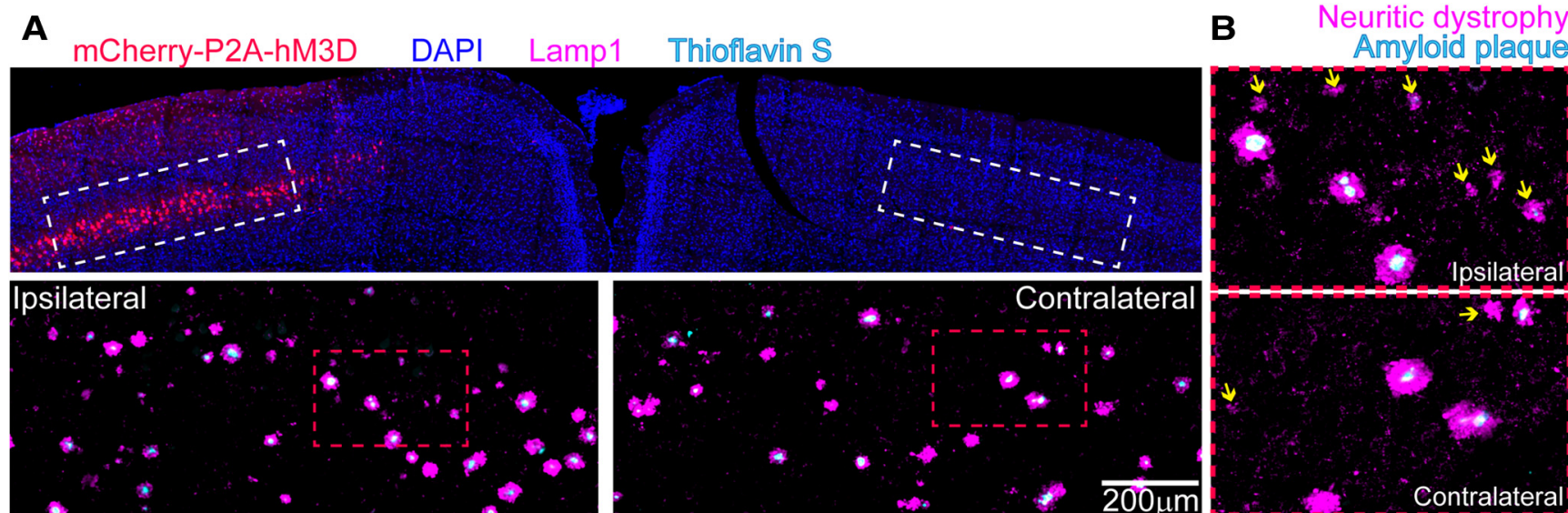

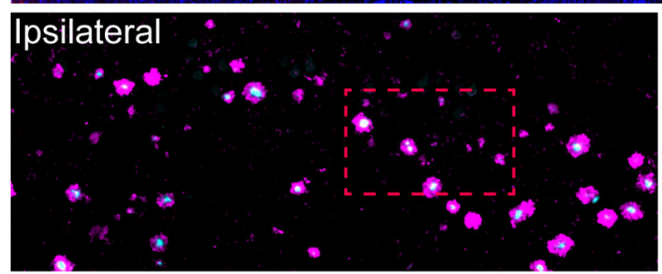

C

GFP-P2A-hM4D

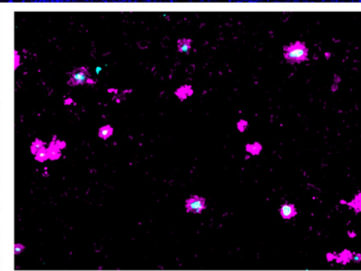

DAPI

\section{Lamp1}

Thioflavin S
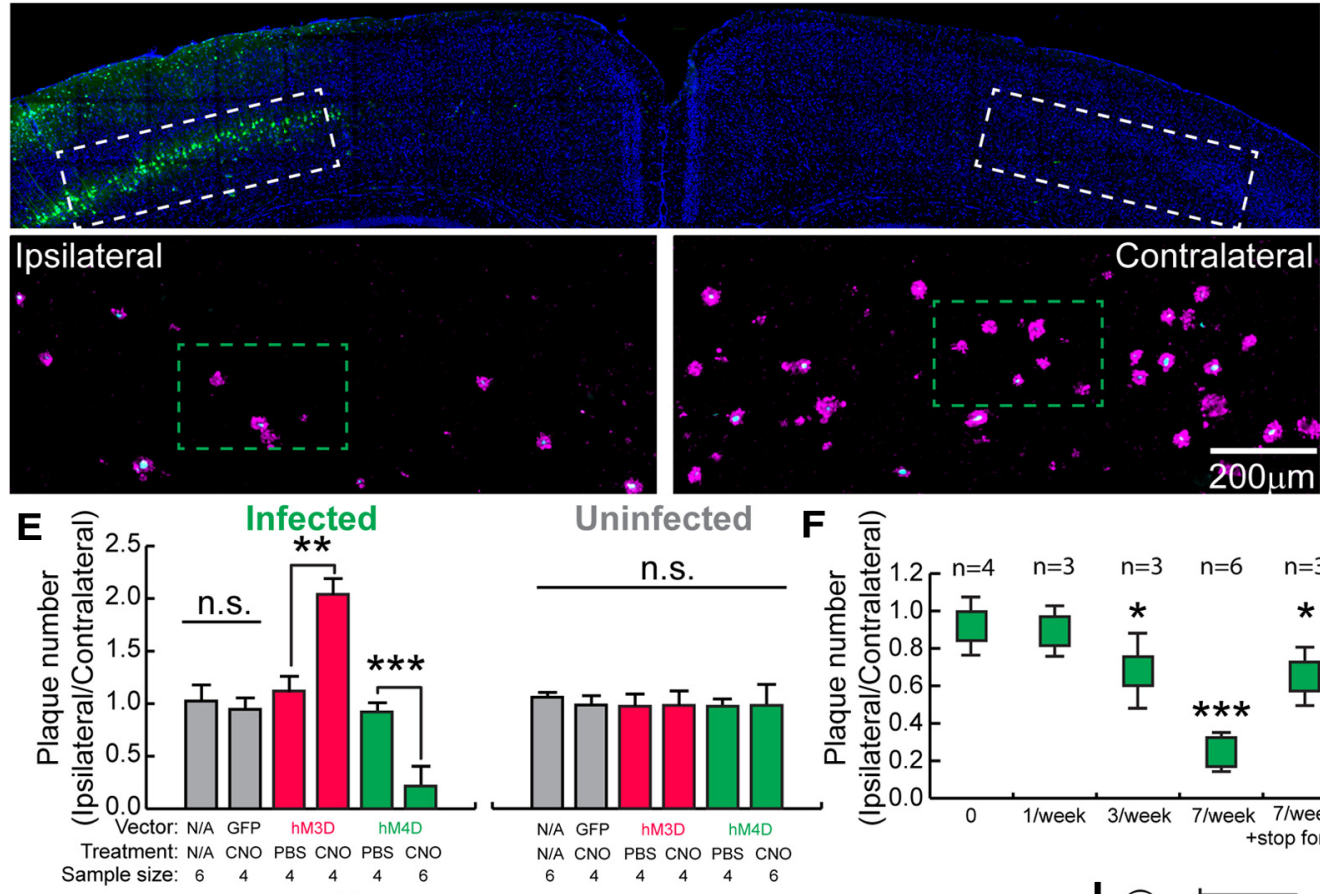

Uninfected
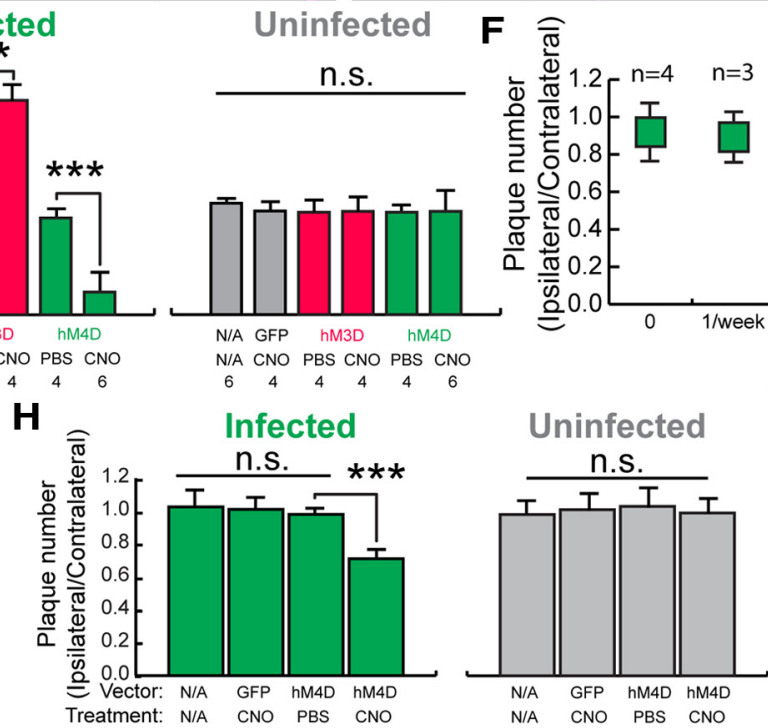

D Neuritic dystrophy Amyloid plaque

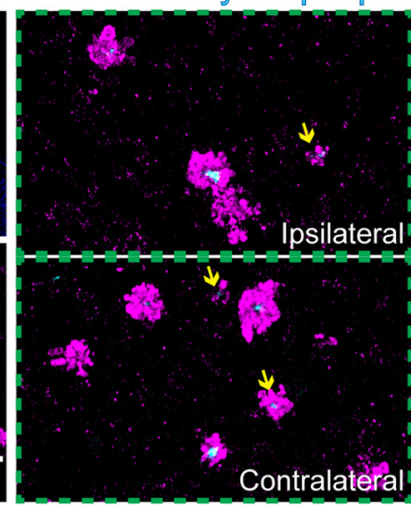

G

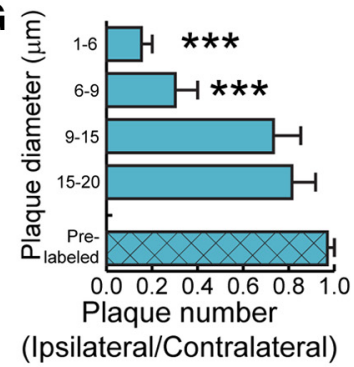

Figure 2. Inhibitory and excitatory DREADDs have opposing effects on fibrillar amyloid deposition. $A-D$, Confocal images of the ipsilateral and contralateral hemispheres in $5 X F A D$ mice treated with hM3D $(\boldsymbol{A}, \boldsymbol{B})$ or hM4D $(\boldsymbol{C}, \boldsymbol{D})$. $\boldsymbol{B}$ and $\boldsymbol{D}$ show zoomed images of amyloid plaques (cyan; labeled by thioflavin $\mathrm{S}$ ) and associated neuritic dystrophy (magenta; labeled by anti-Lamp1 antibody) in the infected cortical region and corresponding region in contralateral hemisphere (red and green dashed boxes). Yellow arrows point to small plaques as determined by the area of thioflavin S labeling. $\boldsymbol{E}$, Quantification of plaque number (ipsilateral/contralateral ratios) in mice receiving different treatment combinations. $\boldsymbol{F}$, Quantification of plaque number (ipsilateral/contralateral ratios) in infected cortical regions of hM4D-treated mice receiving CNO at varying frequencies. G, Quantification of plaque number (ipsilateral/ contralateral ratios classified by plaque size) in infected cortical regions of 5XFAD mice. Last bar (with pattern) shows plaque number in ipsilateral and contralateral regions labeled before hM4D plus CNO treatment, demonstrating no plaque removal over the treatment interval. $n=6$ mice for each group. $\boldsymbol{H}$, Two months hM4D plus CNO treatment in 4-month-old PS/APP mice reduced amyloid deposition in the infected cortical regions. Neither CNO administration nor AAV-hM4D transfection alone produced significant changes in amyloid deposition. $n=$ 3 mice for each group. $\boldsymbol{I}$, Quantification of plaque number (ipsilateral/contralateral ratios classified by plaque size) in infected cortical regions of PS/APP mice. In all analyses (E-I), the number of plaques counted in each mouse were $150-300$. Sample size $(n)$ represents animal number. ${ }^{*} p<0.05 ;{ }^{* *} p<0.01 ;{ }^{* * *} p<0.001$. 
A
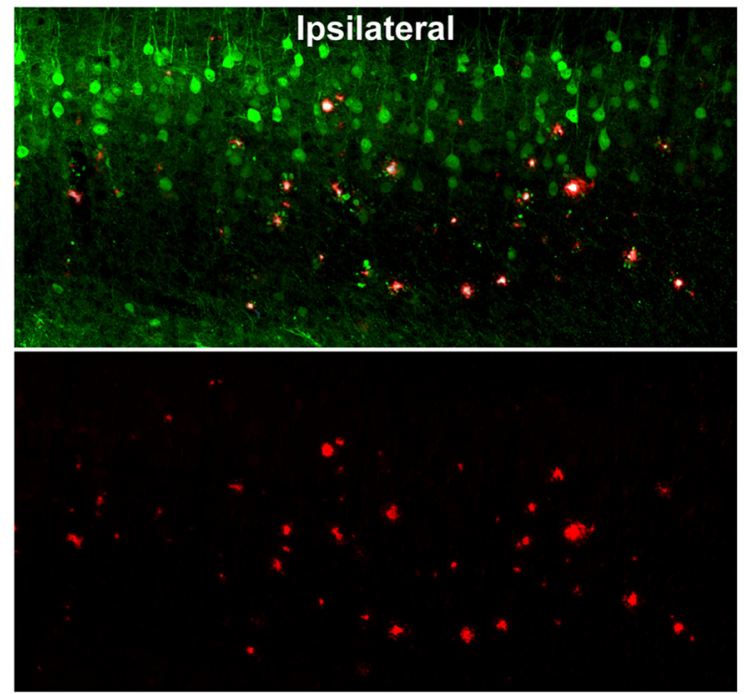

B

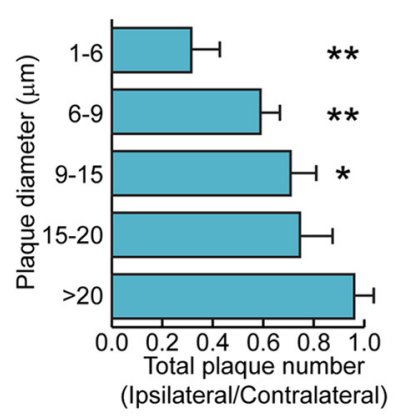

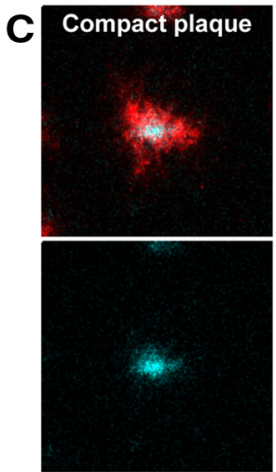

anti-A $\beta$ Thioflavin S

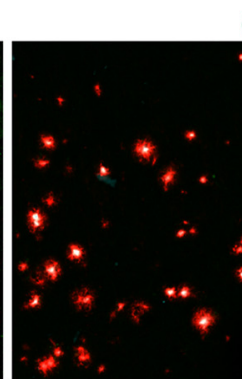

GFP-P2A-hM4D anti-A $\beta$ Thioflavin S
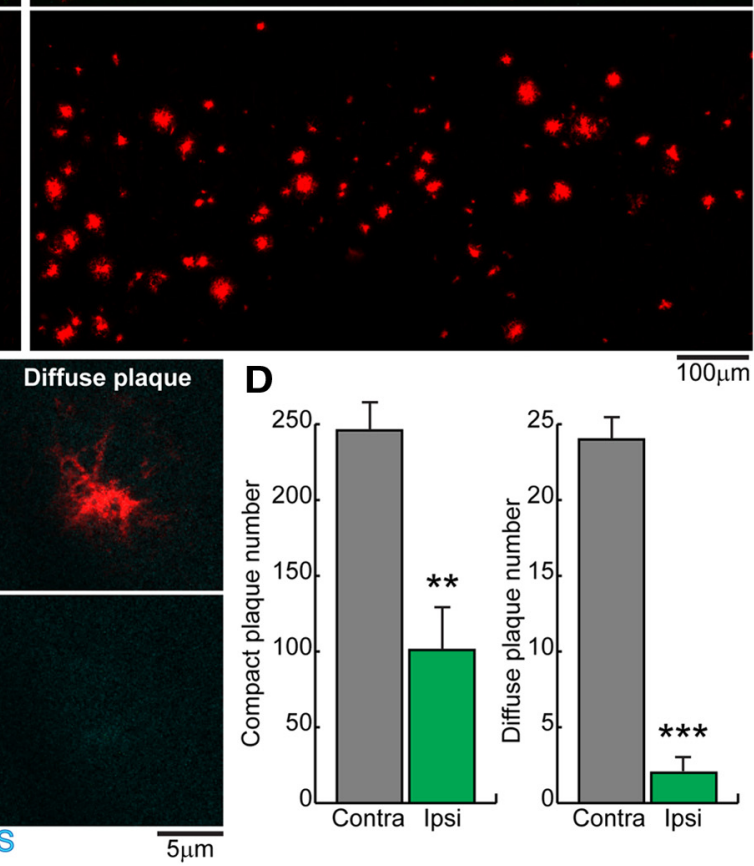

Contralateral

D

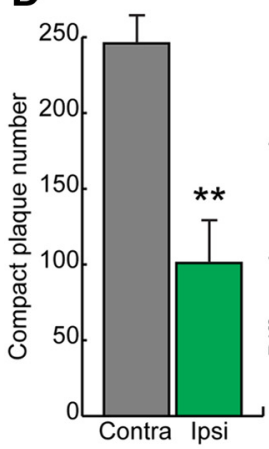

$\overline{100 \mu \mathrm{m}}$

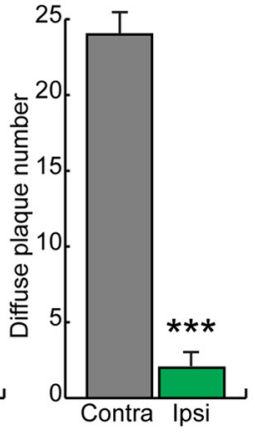

Figure 3. Inhibitory DREADDs markedly reduce diffuse amyloid deposits. $A$, Confocal images of amyloid plaques, double labeled by anti-A $\beta$ antibody (red) and thioflavin $S$ (cyan), in the ipsilateral and contralateral hemispheres of 5 XFAD mice treated with hM4D plus CNO. B, Quantification of plaque number using anti-A $\beta$ immunohistochemistry (ipsilateral/contralateral ratios classified by plaque size) in infected cortical regions of 5 XFAD mice. $n=6$ mice, $150-300$ plaques were counted in each animal. $C$, Examples of compact and diffuse plaques in 5 XFAD mice. Images were maximal projections along z-axis covering the entire plaque. $D$, Quantification of compact and diffuse plaque number in cortical regions receiving hM4D plus CNO treatment and corresponding contralateral regions in 5 XFAD mice. $n=6$ mice. ${ }^{*} p<0.05 ;{ }^{* *} p<0.01 ;{ }^{* * *} p<0.001$.

unpaired Student's $t$ tests were used for comparisons between two groups. For comparing $\mathrm{A} \beta$ concentrations measured by ELISA, twotailed paired $t$ tests were applied between DREADD-treated ipsilateral and contralateral hemispheres. A probability of $p<0.05$ was considered indicative of significant differences between groups. In analyzing plaque number in different size groups (see Fig. $2 G, I$ ), confidence intervals were calculated at indicated significance level and compared with 1.

\section{Results}

To directly test the effects of neural activity on $\mathrm{A} \beta$ deposition and associated neuropathology in vivo, we implemented a chemogenetic approach with DREADDs (Armbruster et al., 2007) targeted to brain regions prone to amyloid deposition in two different transgenic mouse models (5XFAD and PS/APP). We used focal stereotaxic microinjections or subarachnoid infusion of an AAV2 (Fig. 1A) to deliver the excitatory (hM3D) or the inhibitory (hM4D) DREADDs, which are engineered muscarinic G-protein-coupled receptors that are activated selectively by the small-molecule $\mathrm{CNO}$ to induce neuron depolarization or hyperpolarization (Armbruster et al., 2007; Fig. 1B). The infection with AAV2 and chemogenetic manipulation did not induce any detectable inflammation or tissue disruption (Fig. $1 C-G$ ).

In both 5XFAD and PS/APP mice, we administered single daily injections of CNO for 30 or $60 \mathrm{~d}$, which is known to alter neural activity for $\sim 6 \mathrm{~h} /$ injection (Alexander et al., 2009). Treatment with the excitatory AAV-hM3D vector led to a significant increase in amyloid plaque numbers in the hemisphere ipsilateral to the AAV injection compared with the contralateral hemisphere (Fig. $2 A, B, E$ ). In contrast, treatment with inhibitory AAV-hM4D vector resulted in a marked reduction in the number of fibrillar amyloid plaques and total levels of $\mathrm{A} \beta$ (Figs. $2 C-$ $E, H, 4 A, B)$. The reduction in amyloid plaque number was further confirmed by quantification of anti-A $\beta$ immunohistochemistry (Fig. $3 A, B$ ). The degree of amyloid plaque reduction was proportional to the frequency of $\mathrm{CNO}$ administration and was partially reversible when CNO treatment was halted for $30 \mathrm{~d}$ (Fig. 2F). The strongest effect was observed in the smaller and most abundant plaque size population (1-6 $\mu \mathrm{m}$ in diameter), which was diminished by 85 and $60 \%$ in 5XFAD and PS/APP mice, respectively (Fig. 2G,I). Similarly, diffuse plaques (anti-A $\beta$ positive and thioflavin $S$ negative) showed $>90 \%$ reduction after hM4D plus CNO treatment (Fig. $3 C, D$ ). In contrast, no difference was observed in the number of larger plaques $(>15 \mu \mathrm{m}$ in diameter; Figs. $2 G, I, 3 B$ ). Given that small plaques and diffuse plaques are likely to be the most recently formed (Liu et al., 2010; Condello et al., 2011), these data suggest that neural activity significantly influences the formation of new plaques but does not 
A

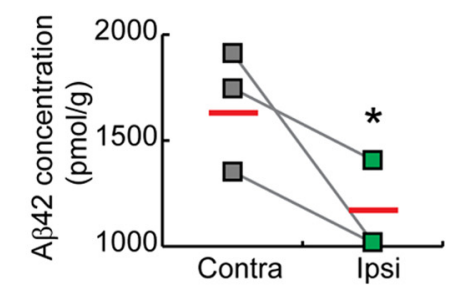

B

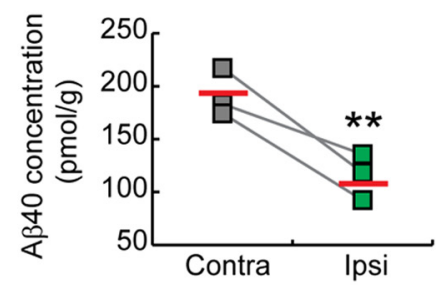

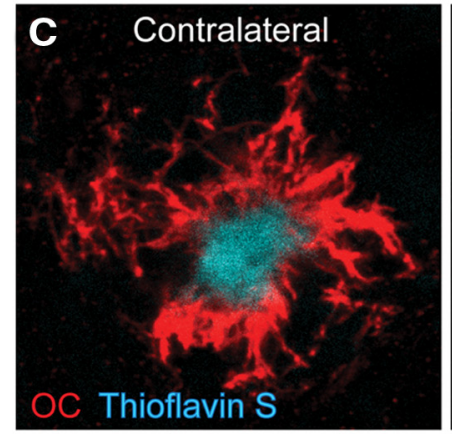
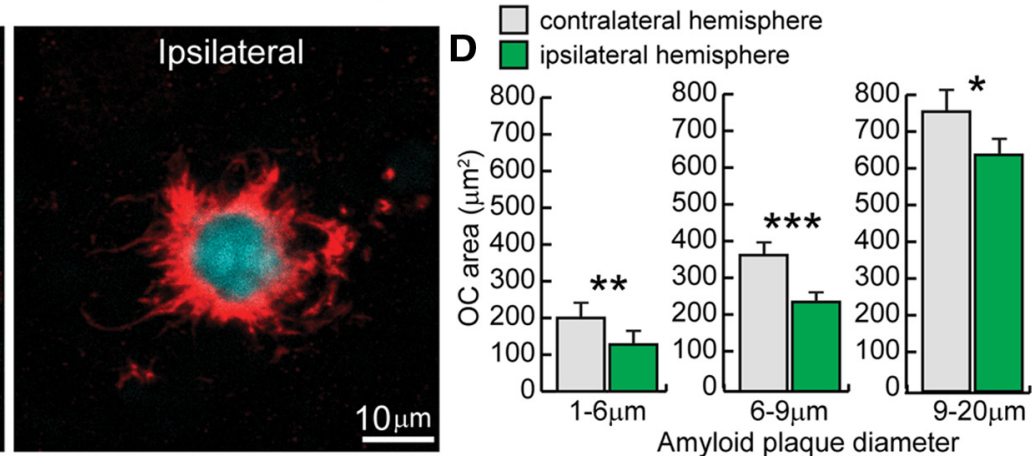

Figure 4. hM4D treatment reduces total $A \beta$ levels and the size of oligomeric $A \beta$ halo around amyloid plaques. $A, B, Q$ uantification of $A \beta_{40}$ and $A \beta_{42}$ concentration by ELISA. $n=3$ mice for each group. C, Confocal images of $O C$ antibody staining of oligomeric amyloid (red) around fibrillar plaque cores (cyan) in ipsilateral and contralateral hemispheres of the same mouse. $D, Q$ Quantification of the area of the $\mathrm{OC}^{+}$amyloid halo showed reduced size in the ipsilateral treated hemisphere. $n=6$ mice for each group, 50 plaques from each mouse were measured. ${ }^{*} p<0.05 ;{ }^{* *} p<0.01$; ${ }^{* * *} p<0.001$.

alter the clearance of older ones. Furthermore, quantification of plaques prelabeled in vivo, before $\mathrm{CNO}$ treatment, with an amyloid-binding fluorescent dye that stably attaches to plaques over months (Condello et al., 2011), did not reveal any difference in the density of preexisting plaques after a $30 \mathrm{~d}$ CNO treatment (Fig. 2G). These data confirm that changes in neural activity affect amyloid deposition but not its removal.

Fibrillar amyloid plaques are surrounded by a halo of oligomeric and protofibrillar $\mathrm{A} \beta$, the size of which is highly correlated with the degree of axonal dystrophy and synapse loss in the vicinity of plaques (Condello et al., 2015). Thus, we tested whether AAV-hM4D treatment had any effect on the size of this $\mathrm{A} \beta$ halo. In all plaque size groups, we observed a reduction in the diameter of the halo, indicating that neural activity reduction likely leads to a decrease in $A \beta$ production and a consequent reduction of outward radial growth of the $\mathrm{A} \beta$ halo (Fig. $4 C, D$ ). Given the reduction in halo size, we next asked to what extent inhibition of activity influences the density of synaptic markers in the vicinity of amyloid plaques and the magnitude of dystrophic axonal abnormalities. Quantification of synaptic puncta, immunolabeled with the postsynaptic marker PSD95, demonstrated that plaques in hM4D-expressing regions had a significantly greater synaptic density in their vicinity than those in contralateral non-infected regions (Fig. $5 A, B$ ). Furthermore, in the treated regions, the degree of axonal dystrophy around plaques was significantly reduced (Fig. 5D-G). In contrast, increasing neural activity by hM3D treatment led to exacerbation of axonal dystrophy around plaques (Fig. 5D). This indicates that, in addition to changing total plaque number, chronic modulation of neural activity directly affects the degree of synaptic disruption around individual plaques. Although such changes are likely attributable to the observed differences in size of the $A \beta$ halo, it is also possible that activity may exert direct effects on neuronal susceptibility to amyloid toxicity.

We next explored the possible mechanisms through which DREADDs affect amyloid deposition and associated pathologies.
DREADD activation is likely to trigger multiple downstream signaling pathways mediated through mitogen-activated protein kinase, phospholipase-C, and adenylate cyclase, all of which have the potential for modulating APP processing (Thathiah and De Strooper, 2011). However, the predicted directionality of their effect is opposite to what we see experimentally. Thus, given that two subtypes of DREADDs have opposing effects on neural activity (Fig. 1; Armbruster et al., 2007) and amyloid deposition (Fig. 2), it is likely that the net changes we observed are predominantly modulated by neural activity rather than by the abovementioned signaling pathways.

Previous studies suggest that neuronal activity can modulate $\mathrm{A} \beta$ peptide release at presynaptic terminals and somatodendritic fields (Wei et al., 2010) through synaptic vesicular mechanisms (Cirrito et al., 2008) or nonsynaptic neuropeptidelike secretion (Ludwig and Leng, 2006). However, the contribution of presynaptic and postsynaptic sites to the long-term accumulation of amyloid plaques remains unknown. To determine their contributions, we examined the thalamic nuclei in which axons of DREADD-expressing cortical layer $\mathrm{V}$ neurons projected (Fig. $6 A$ ). After $30 \mathrm{~d}$ of $\mathrm{CNO}$ treatment, we observed a decrease in amyloid plaque number in thalamic projection areas of mice expressing hM4D, whereas those expressing hM3D demonstrated a significant increase in plaques (Fig. $6 \mathrm{~B}, \mathrm{C}$ ). Importantly, DREADD treatment did not change c-Fos levels in the somata of LP neurons (Fig. 6D), suggesting that the observed changes in plaque number were likely attributable to modulation of $\mathrm{A} \beta$ release from axon terminals of DREADD-expressing cortical layer $\mathrm{V}$ neurons rather than local release by LP neurons. In addition, hM4D expression in CA1 pyramidal neurons of the hippocampus led to a reduction in amyloid plaques in adjacent regions containing only their dendritic fields (Fig. $6 E-G$ ). The plaque reduction in axonal and somatodendritic fields was of similar magnitude $(-39 \%$ in axonal field and $-55 \%$ in somatodendritic field), suggesting that both synaptic vesicular and non- 

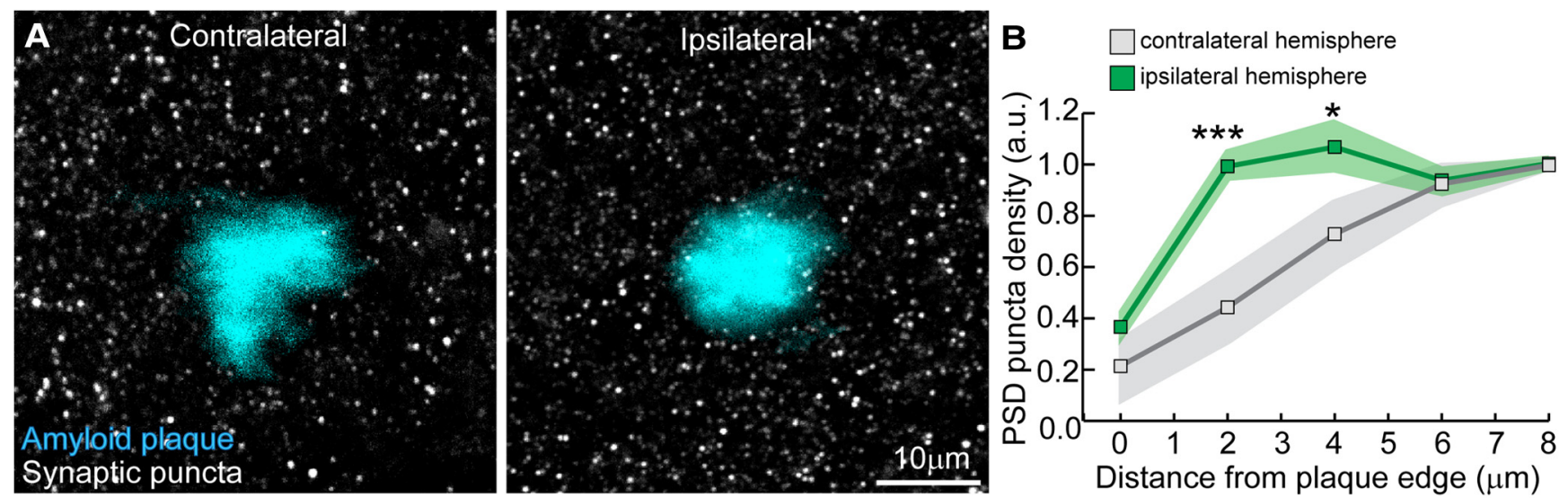

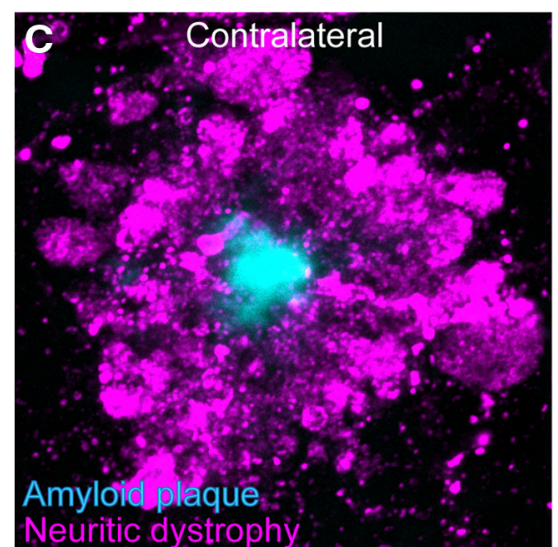

$\mathbf{E}$

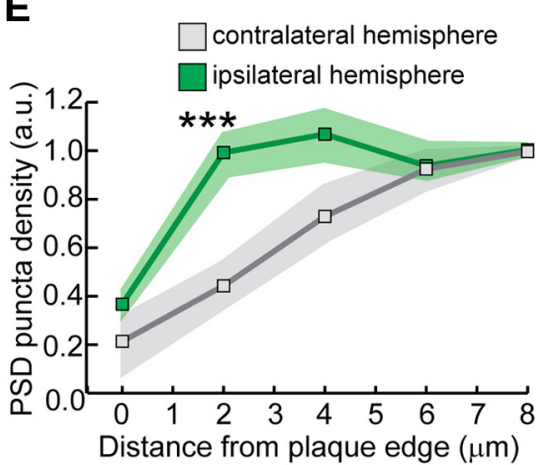

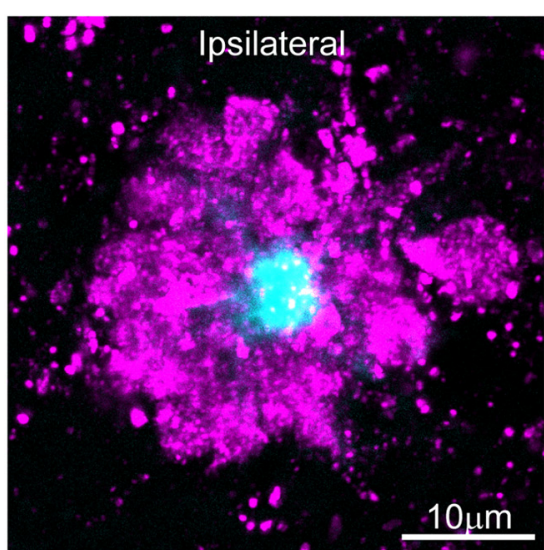

$\mathbf{F}$

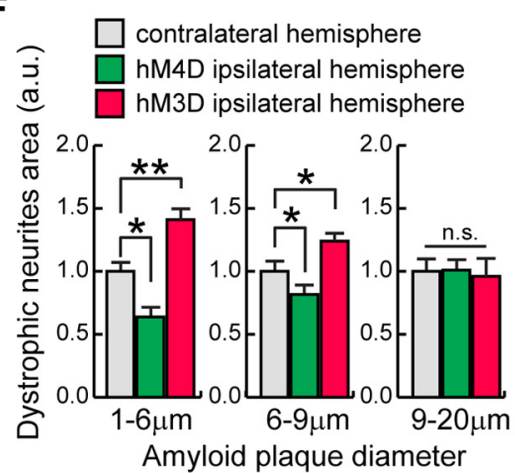

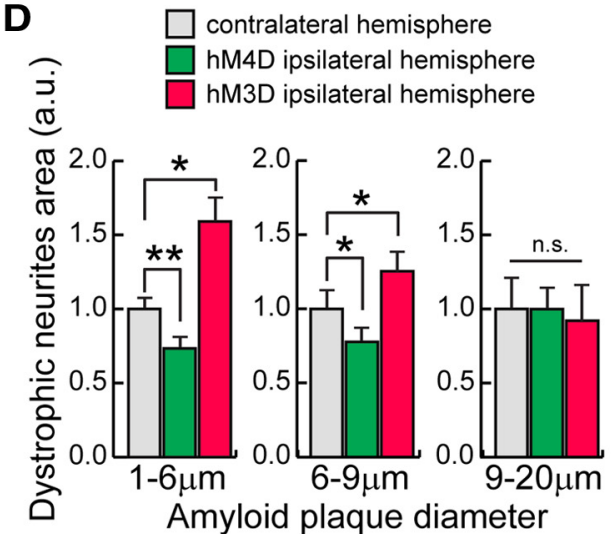

G

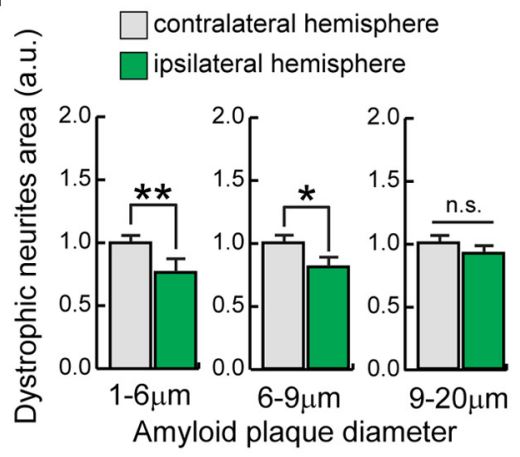

Figure 5. hM3D and hM4D chemogenetic treatment has opposite effects on the degree of synaptic pathology around amyloid plaques. $A$, Images of synaptic puncta (white; labeled by anti-PSD95 antibody) around amyloid plaques (cyan; labeled by thioflavin S). B, Quantification of synaptic density in mice that received hM4D treatment shows greater density of PSD95 puncta near amyloid plaques in the ipsilateral compared with contralateral hemispheres. $\boldsymbol{C}$, Images of axonal dystrophy labeled with an antibody against Lamp1 (magenta) around amyloid plaques (cyan; labeled by thioflavin S) in ipsilateral and contralateral hemispheres of hM4D plus (NO treated mice. D, Quantification of axonal dystrophy area in mice that received hM4D or hM3D treatment. $n=6$ mice in the hM4D group and 4 mice in the hM3D group. Fifty plaques were imaged in each animal for all the analyses. Statistical analyses were done using animal number as $n$. $\boldsymbol{E}, \boldsymbol{F}$, Statistical analyses of data in $\boldsymbol{B}$ and $\boldsymbol{D}$ using plaque number as $n$ are consistent with analysis by animal number. $\boldsymbol{G}$, Quantification of area of dystrophic neurites labeled using APP immunohistochemistry in mice that received hM4D plus CNO treatment. ${ }^{*} p<0.05 ;{ }^{* *} p<0.01 ;{ }^{* * *} p<0.001$.

synaptic somatodendritic release provide robust mechanisms for $\mathrm{A} \beta$ secretion and plaque deposition.

The effect of neural activity on plaque deposition is likely mediated through its effect on $\mathrm{A} \beta$ release or APP processing given that we did not observe changes in the levels of various control proteins, as well as APP processing and $A \beta$-degrading enzymes (Fig. 7A). Interestingly, $\mathrm{CNO}$ treatment increased the amount of intracellular APP in neurons infected with hM4D and downregulated APP in those expressing hM3D (Fig. 7A,B). The directionality of these changes indicates that APP gene transcription cannot account for the differential accumulation of amyloid plaques with observed with chemogenetic treatment. Instead, the accumulation of APP is likely to be attributable to changes in APP processing capacity that lead to differential buildup of unprocessed APP within the cell body.

\section{Discussion}

Our results indicate that hM4D DREADD gene therapy significantly reduces amyloid deposition. Although the exact mechanisms of this effect remain to be elucidated in future studies, our results suggest the mechanism may involve suppression of activity-dependent $A \beta$ production/secretion and not transcriptional or translational downregulation of genes involved in amyloid biology. This hypothesis is supported by our find- 
A
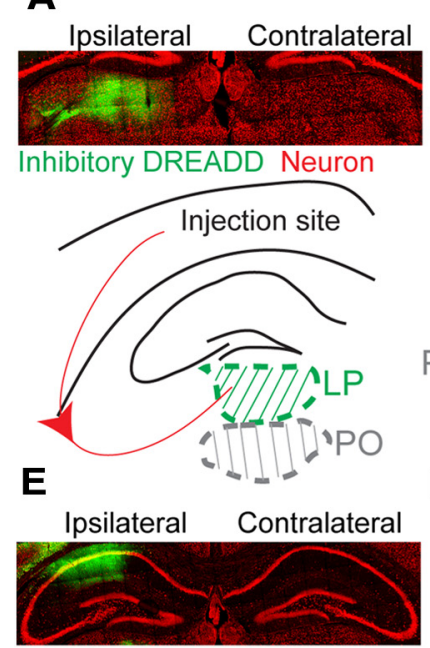

Inhibitory DREADD Neuron

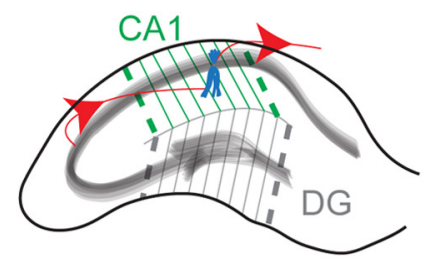

B

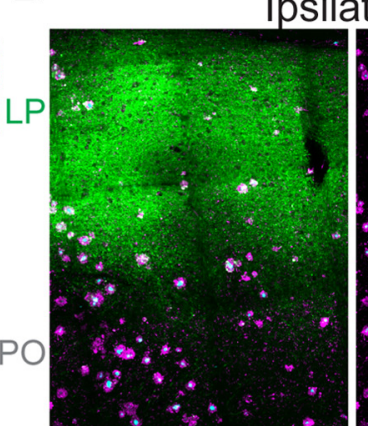

F

F

Inhibitory DREADD Neuritic dystrophy Amyloid plaque

Ipsilateral
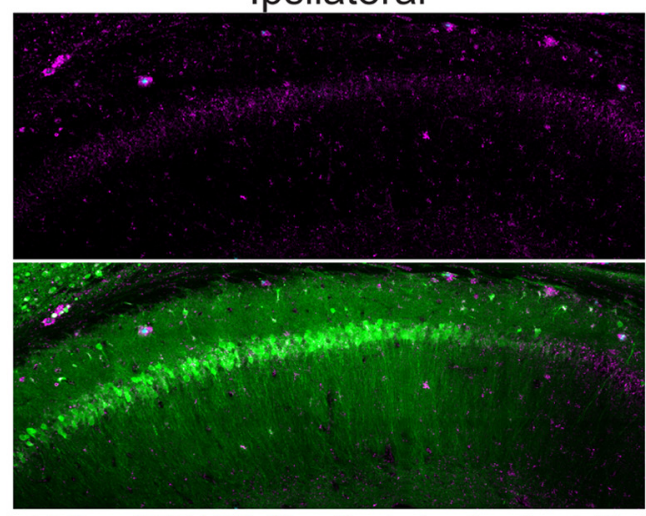

Inhibitory DREADD Neuritic dystrophy Amyloid plaque

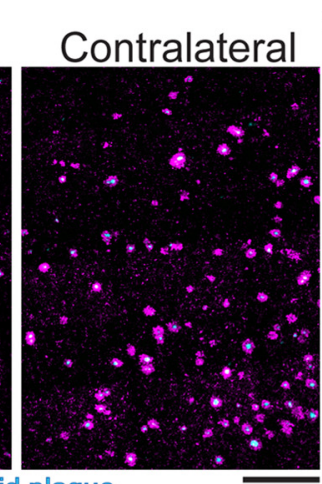

C

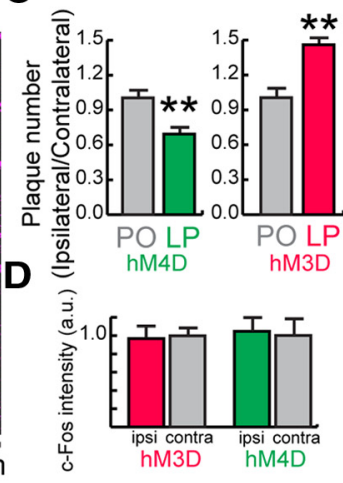

Contralateral

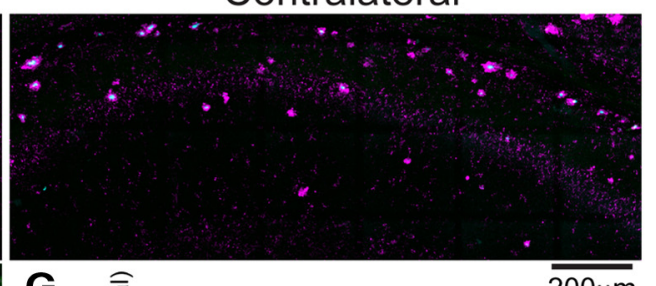

G

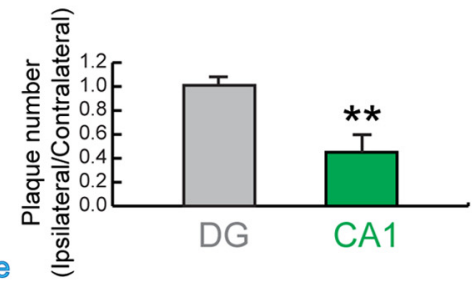

Figure 6. DREADD treatment affects $A \beta$ deposition in both presynaptic and postsynaptic regions. $A, B$, Thalamic LP nucleus, but not the adjacent posterior complex (PO) nucleus, contain axons of cortical neurons infected with inhibitory DREADDs (green). Neuronal cells were labeled with Nissl stain (red). Neuritic dystrophy around plaques were labeled by anti-Lamp1 immunostaining (magenta). C, hM4D and hM3D treatments showed opposite effects on amyloid deposition only in LP (innervated region) but not P0 (adjacent uninnervated region). $n=4$ mice in each group, 60-120 plaques were counted in each region. $D$, Quantification of c-Fos immunostaining in LP neurons. $n=3$ mice, 50 neurons from each animal. $E-G, C A 1$ stratum regions, but not the adjacent dentate gyrus (DG), contain the dendrites of AAV-hM4D-infected CA1 neurons. Chemogenetic manipulation reduced amyloid deposition in the somatodendritic field of CA1 neurons but not the adjacent DG region (upstream polysynaptic connection from CA1). $n=4$ mice in each group, $20-50$ plaques were counted in each region. ${ }^{* *} p<0.01$.

A

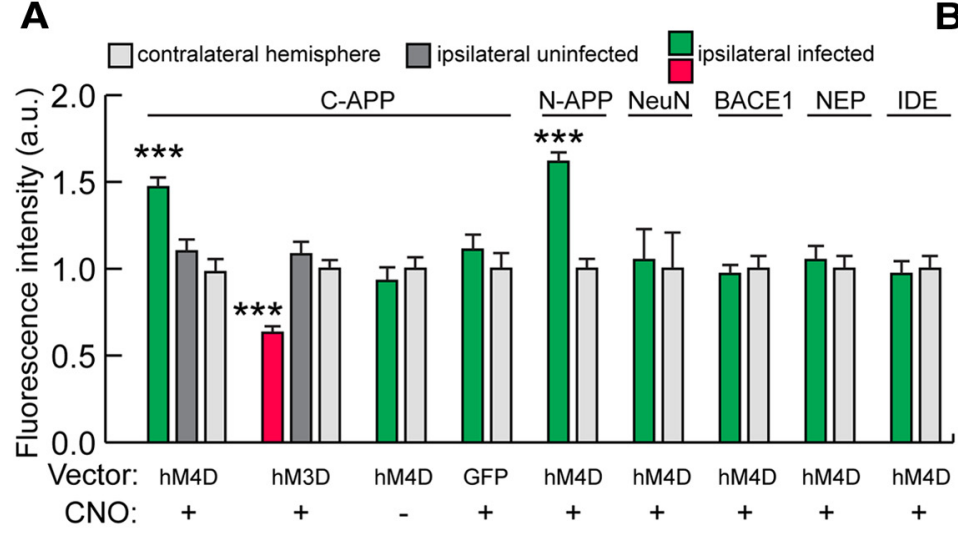

B

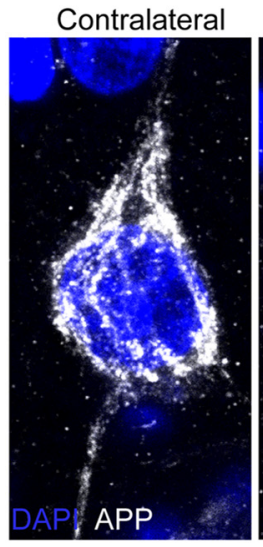

Ipsilateral

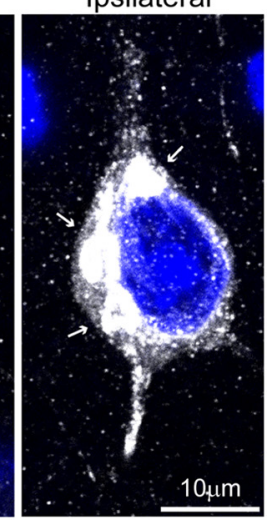

Figure 7. DREADDs likely modulate APP processing and A $\beta$ secretion. $A$, Quantitative immunohistochemistry analyses for APP, NeuN, BACE1, NEP, and IDE proteins in DREADD-treated mice. APP was tested with two antibodies recognizing $C$ - and $N$-terminal sequences. $n=50$ cells from 3 mice for each group. $\boldsymbol{B}$, Confocal images showing a greater degree of APP immunolabeling in the cell body of hM4D infected neurons (arrow; quantified in $A$ ). ${ }^{* * *} p<0.001$.

ings that APP is increased in the somata of AAV-hM4Dinfected and CNO-treated neurons, whereas no changes occur in BACE1, NEP, and IDE levels (Fig. 7). Similar forms of perinuclear APP accumulation have been reported on APP processing suppression in vitro (Goodger et al., 2009). Such an observation suggests that intracellular APP transport may be mechanistically linked with its processing. Alternatively, accu- mulation may occur as a result of the concurrent transgenic APP overexpression and DREADD-induced suppression of APP processing.

DREADDs significantly modulated amyloid deposition in both axonal and somatodendritic fields of infected neurons (Fig. 6). This observation is consistent with a recent in vitro study showing that $A \beta$ can be released from both axons and 
dendrites (DeBoer et al., 2014). Activity-dependent somatodendritic release of neuropeptides is an important signaling mechanism for neuromodulation (Ludwig et al., 2002). Given our results, it is possible that, in addition to synaptic release, $\mathrm{A} \beta$ undergoes somatodendritic release through a similar mechanism as the secretion of neuropeptides. Additional research elucidating this mechanism may identify therapeutic targets that specifically reduce nonsynaptic release of $A \beta$ without disrupting normal neurotransmission.

To our knowledge, our study provides the first demonstration that chronic attenuation of neural activity ameliorates the degree of amyloid deposition and synaptic disruption in mouse models of AD. In combination with previous work (Yamamoto et al., 2015), our study supports the hypothesis that neural activity is a critical driving force of amyloid deposition. Although the effects on $\mathrm{A} \beta$ levels may occur directly by changes in normal neural activity, it is also possible that DREADDs affect the degree of aberrant neural activity that is known to occur in the vicinity of amyloid plaques (Busche et al., 2008). The reduction in synaptic loss and axonal dystrophy that we observed with inhibitory hM4D suggests that aberrant activity may increase susceptibility of neurons to $A \beta$. The neuroprotective effects of hM4D treatment could be attributable to the reduction in the size of the protofibrillar $\mathrm{A} \beta$ halo around plaques, as well as a direct effect of activity modulation on neuronal susceptibility to $A \beta$ toxicity. Interestingly, our experiments with DREADDs involved a single daily dose of $\mathrm{CNO}$ that has been shown to exert an effect on neural activity of only $\sim 6 \mathrm{~h}$ (Alexander et al., 2009). Thus, it is conceivable that modulation of neural activity by either pharmacological or gene therapy could serve as a future therapeutic strategy for treating $\mathrm{AD}$, with limited and transient potential negative cognitive side effects.

In light of the well documented evidence for neural hyperactivity occurring in the brains of individuals with early-stage $\mathrm{AD}$ (Bookheimer et al., 2000; Dickerson et al., 2005; Elman et al., 2014), the present study suggests that a vicious cycle may exist between hyperactivity and amyloid deposition. This observation may partially explain the synchronized activity in areas belonging to the default network and their high susceptibility to amyloid depositions (de Haan et al., 2012). Interfering with this vicious cycle by suppressing neuronal activity could therefore provide a way to slow disease progression. Our data provide evidence that the formation of new amyloid plaques can be reduced by suppressing neuronal activity in synaptically connected brain regions. Thus, it is possible that focal treatment of highly connected brain regions (such as the basal forebrain cholinergic system; Cole et al., 2010) could lead to amyloid reduction in the wider brain.

Although brain gene therapy is a challenging therapeutic modality, recent successes with viral-mediated gene therapy in other organs (Ferreira et al., 2014) provides hope that such a strategy may constitute a feasible approach for treating AD. Such a strategy has the advantage of spatial specificity because viral infection can be achieved in broad or focal areas of the brain, which could target the treatment to vulnerable areas. This may be relevant in light of evidence demonstrating stereotyped prion-like pathological spreading through anatomically interconnected circuits (Harris et al., 2010; Nath et al., 2012). In addition, the fact that this treatment effectively ameliorates two aggressive models of amyloidosis suggests that this therapeutic strategy may be most appropriate for rapidly progressive and malignant forms of familial AD. Additional research will be required to determine whether this is a viable approach in familial or sporadic forms of human $\mathrm{AD}$ and in other protein aggregation disorders.

\section{References}

Alexander GM, Rogan SC, Abbas AI, Armbruster BN, Pei Y, Allen JA, Nonneman RJ, Hartmann J, Moy SS, Nicolelis MA, McNamara JO, Roth BL (2009) Remote control of neuronal activity in transgenic mice expressing evolved G protein-coupled receptors. Neuron 63:27-39. CrossRef Medline

Armbruster BN, Li X, Pausch MH, Herlitze S, Roth BL (2007) Evolving the lock to fit the key to create a family of $\mathrm{G}$ protein-coupled receptors potently activated by an inert ligand. Proc Natl Acad Sci U S A 104: 5163-5168. CrossRef Medline

Bero AW, Yan P, Roh JH, Cirrito JR, Stewart FR, Raichle ME, Lee JM, Holtzman DM (2011) Neuronal activity regulates the regional vulnerability to amyloid- $\beta$ deposition. Nat Neurosci 14:750-756. CrossRef Medline

Bookheimer SY, Strojwas MH, Cohen MS, Saunders AM, Pericak-Vance MA, Mazziotta JC, Small GW (2000) Patterns of brain activation in people at risk for Alzheimer's disease. N Engl J Med 343:450-456. CrossRef Medline

Busche MA, Eichhoff G, Adelsberger H, Abramowski D, Wiederhold KH, Haass C, Staufenbiel M, Konnerth A, Garaschuk O (2008) Clusters of hyperactive neurons near amyloid plaques in a mouse model of Alzheimer's disease. Science 321:1686-1689. CrossRef Medline

Cirrito JR, Yamada KA, Finn MB, Sloviter RS, Bales KR, May PC, Schoepp DD, Paul SM, Mennerick S, Holtzman DM (2005) Synaptic activity regulates interstitial fluid amyloid-beta levels in vivo. Neuron 48:913-922. CrossRef Medline

Cirrito JR, Kang JE, Lee J, Stewart FR, Verges DK, Silverio LM, Bu G, Mennerick S, Holtzman DM (2008) Endocytosis is required for synaptic activity-dependent release of amyloid-beta in vivo. Neuron 58:42-51. CrossRef Medline

Cole MW, Pathak S, Schneider W (2010) Identifying the brain's most globally connected regions. Neuroimage 49:3132-3148. CrossRef Medline

Condello C, Schain A, Grutzendler J (2011) Multicolor time-stamp reveals the dynamics and toxicity of amyloid deposition. Sci Rep 1:19. CrossRef Medline

Condello C, Yuan P, Schain A, Grutzendler J (2015) Microglia constitute a barrier that prevents neurotoxic protofibrillar $A \beta 42$ hotspots around plaques. Nat Commun 6:6176. CrossRef Medline

DeBoer SR, Dolios G, Wang R, Sisodia SS (2014) Differential release of -amyloid from dendrite- versus axon-targeted APP. J Neurosci 34: 12313-12327. CrossRef Medline

de Haan W, Mott K, van Straaten EC, Scheltens P, Stam CJ (2012) Activity dependent degeneration explains hub vulnerability in Alzheimer's disease (Sporns O, ed). PLoS Comput Biol 8:e1002582. CrossRef Medline

Dickerson BC, Salat DH, Greve DN, Chua EF, Rand-Giovannetti E, Rentz DM, Bertram L, Mullin K, Tanzi RE, Blacker D, Albert MS, Sperling RA (2005) Increased hippocampal activation in mild cognitive impairment compared to normal aging and AD. Neurology 65:404-411. CrossRef Medline

Elman JA, Oh H, Madison CM, Baker SL, Vogel JW, Marks SM, Crowley S, O'Neil JP, Jagust WJ (2014) Neural compensation in older people with brain amyloid- $\beta$ deposition. Nat Neurosci 17:1316-1318. CrossRef Medline

Ferreira V, Petry H, Salmon F (2014) Immune responses to AAV-vectors, the Glybera example from bench to bedside. Front Immunol 5:82. CrossRef Medline

Goodger ZV, Rajendran L, Trutzel A, Kohli BM, Nitsch RM, Konietzko U (2009) Nuclear signaling by the APP intracellular domain occurs predominantly through the amyloidogenic processing pathway. J Cell Sci 122:3703-3714. CrossRef Medline

Gowrishankar S, Yuan P, Wu Y, Schrag M, Paradise S, Grutzendler J, De Camilli P, Ferguson SM (2015) Massive accumulation of luminal protease-deficient axonal lysosomes at Alzheimer's disease amyloid plaques. Proc Natl Acad Sci U S A 112:E3699-E3708. CrossRef Medline

Harris JA, Devidze N, Verret L, Ho K, Halabisky B, Thwin MT, Kim D, Hamto P, Lo I, Yu GQ, Palop JJ, Masliah E, Mucke L (2010) Transsynaptic progression of amyloid- $\beta$-induced neuronal dysfunction within the entorhinal-hippocampal network. Neuron 68:428-441. CrossRef Medline

Kamenetz F, Tomita T, Hsieh H, Seabrook G, Borchelt D, Iwatsubo T, Sisodia 
S, Malinow R (2003) APP processing and synaptic function. Neuron 37:925-937. CrossRef Medline

Kim JH, Lee SR, Li LH, Park HJ, Park JH, Lee KY, Kim MK, Shin BA, Choi SY (2011) High cleavage efficiency of a 2A peptide derived from porcine teschovirus-1 in human cell lines, zebrafish and mice (Thiel V, ed). PLoS One 6:e18556. CrossRef Medline

Liu Z, Condello C, Schain A, Harb R, Grutzendler J (2010) CX3CR1 in microglia regulates brain amyloid deposition through selective protofibrillar amyloid- $\beta$ phagocytosis. J Neurosci 30:17091-17101. CrossRef Medline

Ludwig M, Leng G (2006) Dendritic peptide release and peptide-dependent behaviours. Nat Rev Neurosci 7:126-136. CrossRef Medline

Ludwig M, Sabatier N, Bull PM, Landgraf R, Dayanithi G, Leng G (2002) Intracellular calcium stores regulate activity-dependent neuropeptide release from dendrites. Nature 418:85-89. CrossRef Medline

Nath S, Agholme L, Kurudenkandy FR, Granseth B, Marcusson J, Hallbeck M (2012) Spreading of neurodegenerative pathology via neuron-to-neuron transmission of $\beta$-amyloid. J Neurosci 32:8767-8777. CrossRef Medline
Palop JJ, Chin J, Roberson ED, Wang J, Thwin MT, Bien-Ly N, Yoo J, Ho KO, Yu GQ, Kreitzer A, Finkbeiner S, Noebels JL, Mucke L (2007) Aberrant excitatory neuronal activity and compensatory remodeling of inhibitory hippocampal circuits in mouse models of Alzheimer's disease. Neuron 55:697-711. CrossRef Medline

Thathiah A, De Strooper B (2011) The role of G protein-coupled receptors in the pathology of Alzheimer's disease. Nat Rev Neurosci 12:73-87. CrossRef Medline

Wei W, Nguyen LN, Kessels HW, Hagiwara H, Sisodia S, Malinow R (2010) Amyloid beta from axons and dendrites reduces local spine number and plasticity. Nat Neurosci 13:190-196. CrossRef Medline

Yamamoto K, Tanei Z, Hashimoto T, Wakabayashi T, Okuno H, Naka Y, Yizhar O, Fenno LE, Fukayama M, Bito H, Cirrito JR, Holtzman DM, Deisseroth K, Iwatsubo T (2015) Chronic optogenetic activation augments $\mathrm{A} \beta$ pathology in a mouse model of Alzheimer disease. Cell Rep 11:859-865. CrossRef Medline 